\title{
Utilization and effectiveness of methylprednisolone in a population-based sample of spinal cord injured persons
}

\author{
KA Gerhart ${ }^{1}$, RL Johnson ${ }^{2}$, J Menconi ${ }^{1}$, RE Hoffman ${ }^{1}$ and DP Lammertse ${ }^{3}$ \\ ${ }^{1}$ Craig Hospital, the Rocky Mountain Regional Spinal Injury System, Englewood, Colorado; ${ }^{2}$ The Colorado \\ Department of Public Health and Environment, Denver, Colorado; ${ }^{3}$ Craig Hospital, the Rocky Mountain \\ Regional Spinal Injury System, Englewood, Colorado and the Department of Rehabilitation Medicine at the \\ University of Colorado Health Sciences Center, Denver, Colorado, USA
}

\begin{abstract}
The announcement and publication of the second National Acute Spinal Cord Injury Study (NASCIS II) project's findings regarding the role of high dose methylprednisolone in improving neurological outcomes following acute traumatic spinal cord injury generated widespread excitement and interest. To determine the association between this interest and actual use and implementation of the protocol, Colorado's comprehensive population-based spinal cord injury surveillance data were examined. The medical records of 218 SCI survivors injured between May 1, 1990 and December 31, 1991, and of 145 persons spinal cord injured 2 years later, during 1993, were reviewed to determine the rapidity and extent of NASCIS II implementation by Colorado's hospitals, factors associated with use and non-use of the protocol, changing usage trends over time, and the short term neurological outcomes of patients who received the protocol. Clear documentation of the protocol's usage was present for only $46 \%$ of the reported patients' medical records in 1990-91, and $61 \%$ in 1993 . Small, emergency triage facilities were significantly more likely to use the protocol than larger acute care hospitals, and patients with initially incomplete injuries were less likely to receive the drug. There were no significant differences in neurological outcomes, using the Frankel classification system, between those who received the protocol and those who did not. The limitations and implications of these findings are discussed.
\end{abstract}

Keywords: spinal cord injury; methylprednisolone; outcomes; treatment

\section{Introduction}

Methylprednisolone's role in improving neurological outcomes following acute spinal cord injury was first documented in the second National Acute Spinal Cord Injury Study (NASCIS II) by Michael Bracken and his co-authors. ${ }^{1}$ However, even before this article appeared in a scientific professional journal, its findings received unprecedented publicity. Results, instructions, and drug administration protocols were 'prereleased' ${ }^{2}$ and disseminated by the United Sates government's National Institutes of Health in the form of clinical alerts and other statements directed at physicians. ${ }^{3}$ At the same time, popularized versions of the study's results made their way into the press and other mass media as well. ${ }^{4,5}$

Although this manner of pre-publication dissemination was questioned at the time and still provokes discussion and controversy, ${ }^{2}$ the administration of methylprednisolone according to NASCIS II protocol to persons with acute spinal cord injuries has become the standard of care in the United States. However, to date there have been no follow-up studies that have attempted to replicate the findings of NASCIS II, and none are likely to be pursued in the US, due to medical, legal, and financial constraints. Moreover, the wide- spread publicity surrounding this protocol's alleged efficacy makes further placebo-controlled studies-in which some participants would not receive a seemingly beneficial therapeutic regimen-highly problematic from practical, ethical and legal perspectives.

Such extensive publicity has impacted routine clinical care as well. Indeed, it has been suggested that since the dissemination of the NASCIS II findings, any US physician who does not use the protocol places him or herself in 'severe legal jeopardy'. ${ }^{2}$ Given this, it seems reasonable to hypothesize that virtually all patients in the United States with new acute traumatic spinal cord injuries receive methylprednisolone, and that they receive it in accordance with NASCIS II protocol guidelines (initial bolus of methylprednisolone within $8 \mathrm{~h}$ of injury $-30 \mathrm{mg} \mathrm{kg}^{-1}$ body weight - followed by $5.4 \mathrm{mg}$ methylprednisolone $\mathrm{kg}^{-1}$ body weight every hour for $23 \mathrm{~h}$ as a continuous infusion).

To test this hypothesis, a retrospective analysis of Colorado's population-based sample of traumatic spinal cord injury survivors was undertaken, with the following specific objectives:

1 to determine the speed and extent of NASCIS II protocol implementation in Colorado's hospitals;

2 to determine the effect of entry point into the 
health care system on NASCIS II protocol implementation; and

3 to the limited extent made possible by the available data, to compare short term neurological outcomes of patients receiving the NASCIS II protocol with those receiving no methylprednisolone.

\section{Methodology}

Since 1989, Colorado's spinal cord injury surveillance program (the Early Notification System-ENS) has tracked and registered all Coloradans who sustain traumatic spinal cord injuries. Two methods of case identification are used: (1) reporting by clinicians in key Colorado hospitals which provide trauma care to newly-injured individuals, and (2) retrospective reporting by the medical records departments of all Colorado hospitals, utilizing ICD $9^{6}$ diagnostic codes. Over a 5-year period (1989-1993), this method has yielded statewide annual incidence rates ranging from 36 to almost 43 per million. ${ }^{7}$ Although all included cases have documented motor and or sensory impairment at the time of injury (Frankel A-D) ${ }^{8}$ it is important to note that this population-based sample does include a substantial number of individuals who had relatively mild injuries; between 1989 and 1993 almost one-third of the cases identified had been classified as Frankel grade $\mathrm{D}$ upon their admission to the first treating hospital. $^{7}$

Specific assessment of NASCIS II protocol implementation focused initially on individuals injured during the 20 month period between May 1, 1990 (the approximate time during which widespread information about the drug became available) and December 31, 1991. Medical records were reviewed for the 218 patients identified in Colorado during this time period. Specifically, emergency department notes, medication records for the first $48 \mathrm{~h}$ after injury, and physician admission and discharge summaries were abstracted and documentation of steroid usage was recorded. Other demographic variables were noted, particularly those which related to the NASCIS II exclusion criteria. ${ }^{1}$ The hospital to which each patient was admitted from the injury scene was also coded; those facilities caring for the patient only in the emergency department and for less than $24 \mathrm{~h}$, were considered triage centers. To evaluate changing trends during the 20 month period, three specific time periods were examined: May-December 1990, January-June 1991, and July-December 1991.

Then, each spinal cord injury survivor's neurological recovery was assessed. As noted above, initial Frankel grades were assigned based on neurological preservation documented at the time of admission to the hospital following the injury. Discharge Frankel grades were based on the neurological status reported at the end of the patient's initial inpatient rehabilitation; if an incomplete or resolving neurological status meant that rehabilitation was not indicated, the Frankel grade at discharge-to-home was noted. When available, Frankel classifications already made by the physician were recorded; in their absence, grades were assigned, based on thorough medical records review, by a spinal cord injury-experienced registered physical therapist wellversed in the Frankel grading system. Where inadequate documentation left uncertainty between two possible grades, the lesser grade was selected; if at least this level of certainty could not be ascertained, severity was coded 'unknown'. These initial and discharge Frankel classifications were then compared to determine change in neurological status among study group members.

Finally, to determine changes in NASCIS II protocol administration over time, similar analyses were done for all of the 145 spinal cord injured individuals reported to the ENS during 1993. Findings for both groups were described and statistical significance was determined using the $\chi^{2}$ test.

\section{Results}

During the initial 20 month period, there was clear evidence in $46 \%$ of spinal cord injury survivors' medical records (100 of 218 individuals) that methylprednisolone, as per the NASCIS II protocol, had been utilized. For $23 \%$ (51 persons) there was equally clear evidence that no methylprednisolone had been administered (Figure 1).

Administration rate was highest during the 6 month period from January 1 through June 30 1991, and lowest during the months immediately following the announcement of Bracken's findings (May 1-December 31, 1990) (Figure 2). Among the 24 Colorado hospitals that had admitted patients during the study period, none administered the NASCIS II protocol to all of their potentially eligible patients. The two facilities that used the protocol most frequently administered it to two-thirds of their patients with new spinal cord injuries (four of six cases; 12 of 18 cases). Only $29 \%$ of the hospitals administered the NASCIS II protocol to at least half of the patients with spinal cord injuries they admitted; nine facilities never used it at all.

Two years later, the medical records of $61 \%$ of the 145 Coloradans who sustained spinal cord injuries in 1993 contained documentation of methylprednisolone administration according to the NASCIS II protocol. Twenty-seven percent of the patients clearly did not receive methylprednisolone (Figure 1). Again, 24 different hospitals admitted patients; six of these never used the NASCIS II protocol, although two facilities appeared to have administered methylprednisolone at some other or unspecified dosage. The highest administration rate was $80 \%$ in one facility where four of five persons received the NASCIS II protocol.

Although the comparison groups were small, the patient's point of entry into the health care system impacted whether or not the NASCIS II protocol was administered and documented. Those who first received triage at a small emergency department prior to their transfer to a larger facility were significantly more 

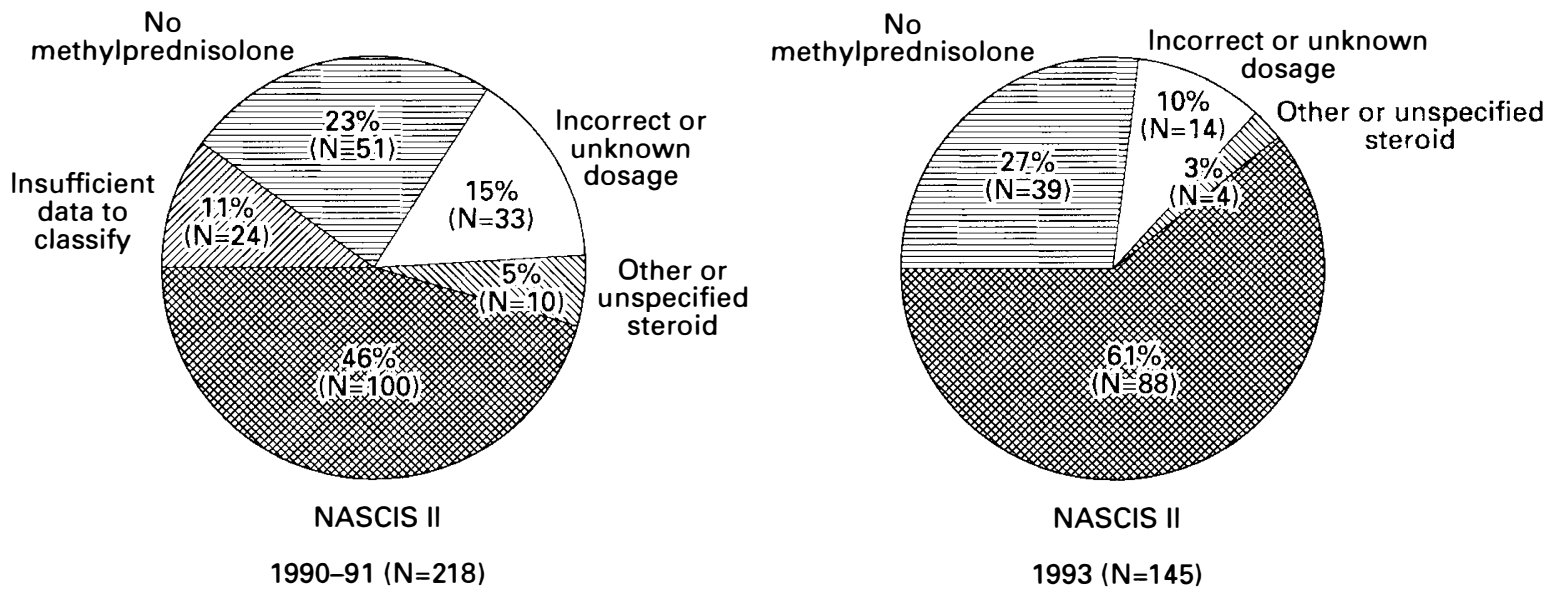

Figure 1 Documentation of steroid administration in SCI survivors' medical records

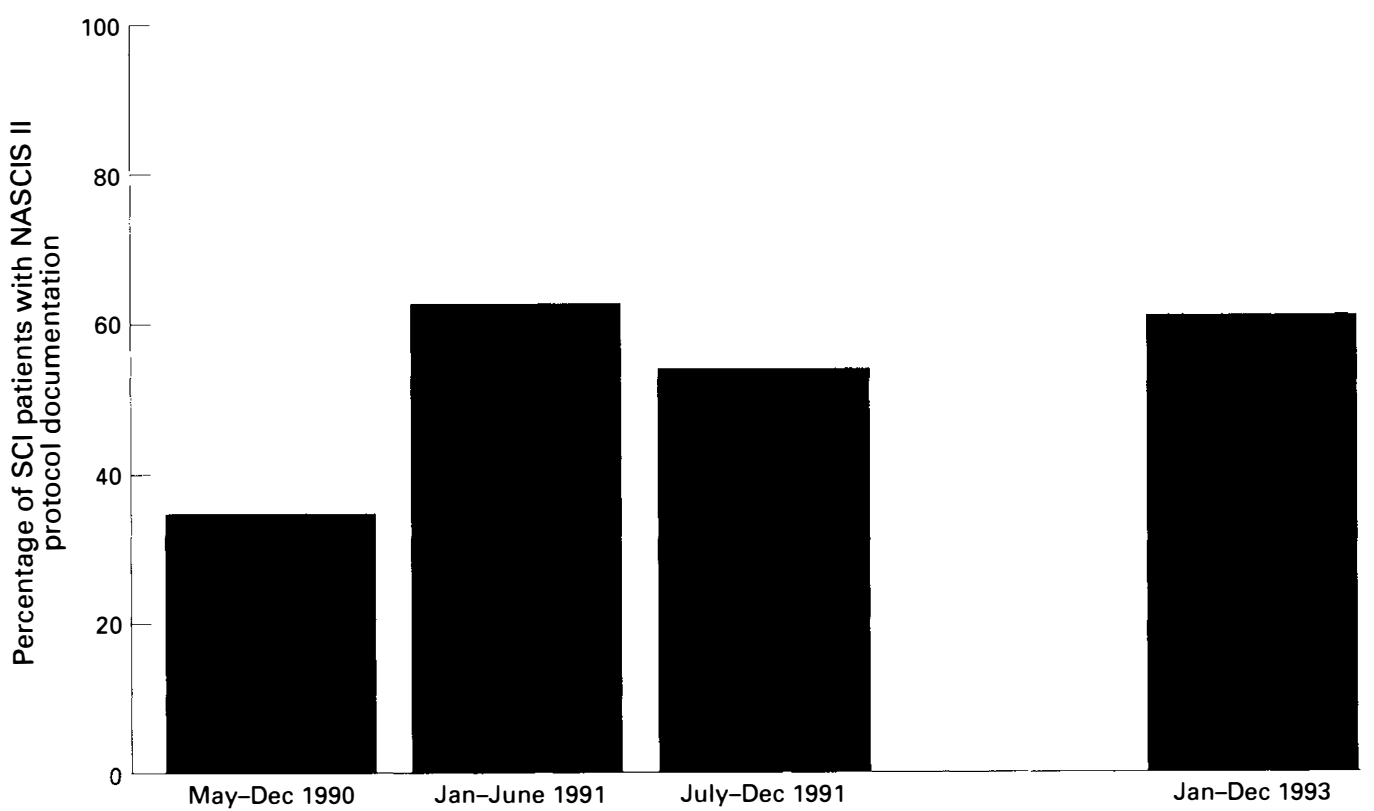

Figure 2 Extent of NASCIS II protocol administration to Colorado SCI patients. (Note: not included on graph. In 1990-91, 17 patients were treated out-of-state; six received NASCIS II protocol. In 1993, 10 patients were treated out-of-state; five received NASCIS II protocol)

likely to be started on the NASCIS II protocol than those admitted immediately to larger acute care hospitals $(P=0.008)$. This trend persisted across the three separate 1990-91 time periods that were examined. Moreover, the trend was even more significant in 1993 $(P=0.003$; Figure 3).

Next, efforts were made to identify patient characteristics that were related to the use of the NASCIS II protocol. As Table 1 shows, individuals with cervical and thoracic injuries and neurologically complete injuries generally received the protocol more frequently than others. In 1990-91, but not in 1993, children under 13 years of age received the protocol less frequently. Individuals with cauda equina injuries and gunshot etiologies-exclusions in the NASCIS II research protocol - still received the methylprednisolone protocol, at least some of the time. There were no known pregnancies among women with new spinal cord injuries in either 1990-91 or 1993, and several of Bracken et al's other protocol exclusions (specifically narcotics addiction, preinjury steroid usage, and other severe injuries) could not be documented reliably within the ENS's existing database.

Of those who received methylprednisolone according to the NASCIS II protocol during 1990 and 1991, 47\% (regardless of their initial neurological completeness) improved by at least one Frankel grade by the time they were discharged from the hospital. Although only $33 \%$ of those who received no methylprednisolone had similar neurological improvement, the difference between these two groups was not statistically significant $(P=0.118$; Table 2$)$. In 1993 , though the numbers 


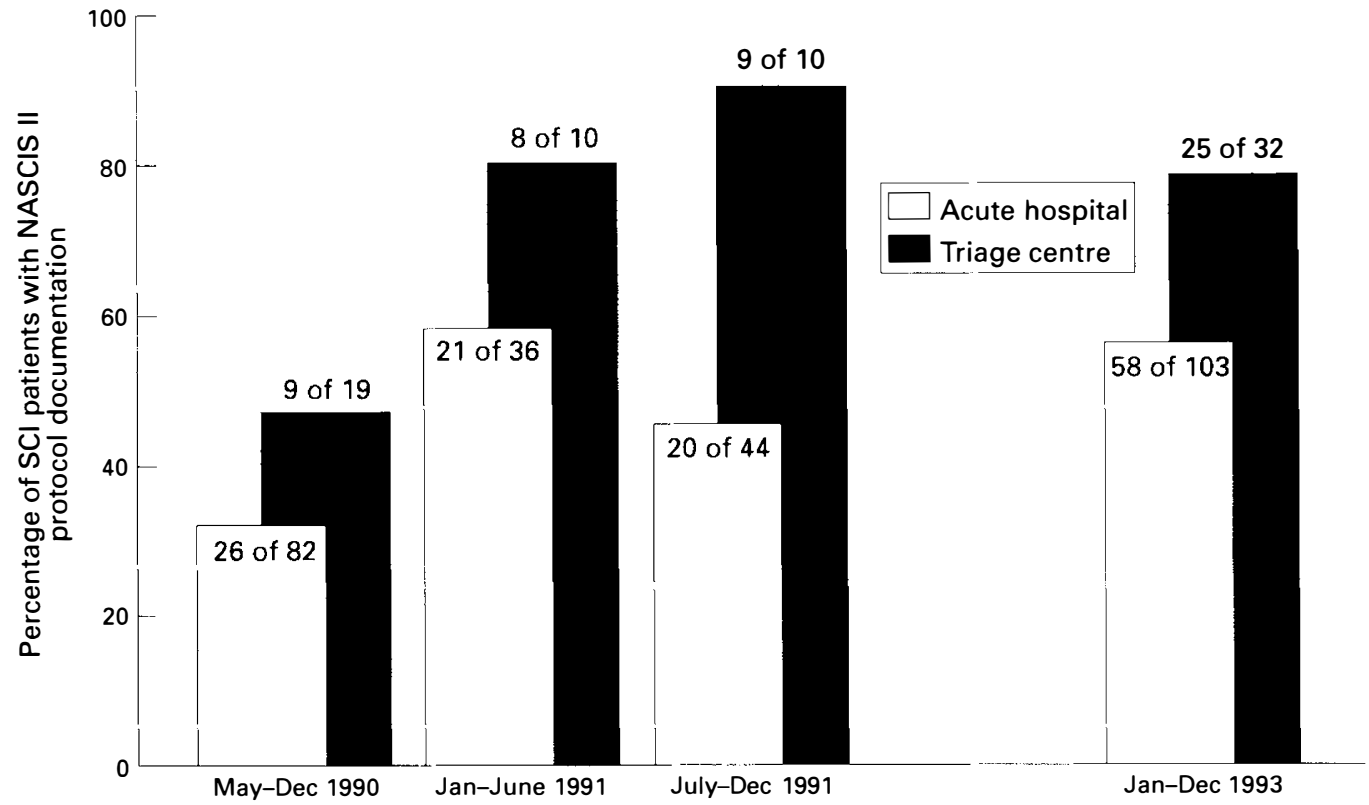

Figure 3 Effect of entry point into the acute care system on NASCIS II protocol administration

Table 1 Factors associated with use of the NASCIS II protocol

\begin{tabular}{|c|c|c|c|c|}
\hline & \multicolumn{2}{|c|}{$1990-91$} & \multicolumn{2}{|c|}{1993} \\
\hline & $\begin{array}{l}\text { No. of cases } \\
\quad(n=218)\end{array}$ & $\begin{array}{l}\text { Received NASCIS II } \\
(n=100)\end{array}$ & $\begin{array}{l}\text { No. of cases } \\
\quad(n=145)\end{array}$ & $\begin{array}{c}\text { Received NASCIS II } \\
(n=88)\end{array}$ \\
\hline \multicolumn{5}{|l|}{ Injury level } \\
\hline Cervical & 119 & $55(46 \%)$ & 82 & $53(65 \%)$ \\
\hline Thoracic & 58 & $20(52 \%)$ & 44 & $28(64 \%)$ \\
\hline Lumbosacral & 41 & $15(37 \%)$ & 19 & $7(37 \%)$ \\
\hline \multicolumn{5}{|l|}{ Injury severity } \\
\hline Frankel A/B & 105 & $58(55 \%)$ & 73 & $54(74 \%)$ \\
\hline Frankel C & 28 & $13(46 \%)$ & 13 & $11(85 \%)$ \\
\hline Frankel D & 80 & $27(34 \%)$ & 47 & $18(38 \%)$ \\
\hline Unknown & 5 & 2 & 12 & 5 \\
\hline \multicolumn{5}{|l|}{ Exclusions cited by Bracken et al } \\
\hline Age $<13$ & 6 & $1(17 \%)$ & 5 & $3(60 \%)$ \\
\hline Pregnancy & 0 & 0 & 0 & 0 \\
\hline Gunshot injury & 13 & $4(31 \%)$ & 8 & $2(25 \%)$ \\
\hline Cauda equina injury (L2 and below) & 13 & $4(31 \%)$ & 8 & $3(38 \%)$ \\
\hline
\end{tabular}

were smaller, the trends were somewhat more significant: $43 \%$ of NASCIS II protocol recipients saw neurological improvement of at least one Frankel grade, compared with $21 \%$ of those who received no methylprednisolone ( $P=0.044$; Table 2$)$.

These same samples were also analyzed applying a stricter outcome criteria: improvement by two or more Frankel grades (Table 3). In 1990-91 there were 71 individuals in the NASCIS II group who had the potential to improve by two or more Frankel grades (ie Frankel A, B, or C at admission). Twenty-one of these spinal cord injury survivors $(30 \%)$ did so. When compared with the group receiving no methylprednisolone ( 22 persons could have improved by two or more grades; five or $23 \%$ did), there was no significant difference $(P=0.486)$. Among the 1993 sample, there also were no significant differences. Sixty-one NASCIS II recipients had the possibility for two grade-level improvement, but only $16(26 \%)$ exhibited such improvement. This was compared with the no methylprednisolone group: among the 12 persons with the potential for a two-level improvement, only three $(25 \%)$ did so $(P=0.942)$.

\section{Discussion}

Although short term neurological outcomes did not differ significantly between methylprednisolone recipients and non-recipients in Colorado, this cannot be 
Table 2 Comparison of short term neurological outcomes with use of the NASCIS II protocol (one or more Frankel grade) (a) 1990-91

\begin{tabular}{|c|c|c|c|c|c|c|}
\hline & \multicolumn{2}{|c|}{$\begin{array}{l}\text { NASCIS II } \\
(n=100)\end{array}$} & \multicolumn{2}{|c|}{$\begin{array}{l}\text { No methylprednisolone } \\
\quad(n=51)\end{array}$} & \multirow{2}{*}{$\begin{array}{c}\text { \% Improved: } \\
\text { NASCIS II } \\
\text { no methylp. }\end{array}$} & \multirow[t]{2}{*}{$P=a$} \\
\hline & $\begin{array}{l}\text { Improved by } \geqslant 1 \\
\text { Frankel grade }\end{array}$ & $\begin{array}{l}\text { No neurological } \\
\text { improvement }\end{array}$ & $\begin{array}{l}\text { Improved by } \geqslant 1 \\
\text { Frankel grade }\end{array}$ & $\begin{array}{l}\text { No neurological } \\
\text { improvement }\end{array}$ & & \\
\hline Frankel A & 21 & 27 & 3 & 9 & $44 \% / 25 \%$ & 0.2356 \\
\hline Frankel B & 8 & 2 & 1 & 2 & $80 \% / 33 \%$ & 0.1245 \\
\hline Frankel C & 9 & 4 & 6 & 1 & $69 \% / 86 \%$ & 0.4167 \\
\hline Frankel D & 8 & 19 & 6 & 20 & $30 \% / 23 \%$ & 0.5885 \\
\hline Total & 46 & 52 & 16 & 32 & $47 \% / 33 \%$ & 0.1181 \\
\hline
\end{tabular}

(b) 1993

\begin{tabular}{|c|c|c|c|c|c|c|}
\hline \multirow[b]{2}{*}{ Frankel A } & \multicolumn{2}{|c|}{$\begin{array}{c}\text { NASCIS II } \\
\quad(n=88)\end{array}$} & \multicolumn{2}{|c|}{$\begin{array}{l}\text { No methylprednisolone } \\
\qquad(n=39)\end{array}$} & \multirow[b]{2}{*}{$31 \% / 33 \%$} & \multirow[b]{2}{*}{0.9596} \\
\hline & 14 & 29 & 4 & 8 & & \\
\hline Frankel B & 5 & 2 & 0 & 0 & $55 \% / 0$ & \\
\hline Frankel C & 10 & 1 & 0 & 0 & $91 \% / 0$ & \\
\hline Frankel D & 4 & 12 & 2 & 14 & $25 \% / 12 \%$ & 0.3650 \\
\hline Total & 33 & 44 & 6 & 22 & $43 \% / 33 \%$ & 0.0444 \\
\hline
\end{tabular}

a Significance was determined using uncorrected $\chi^{2}$. However, for cells with less than 5, Fisher's $\chi^{2}$ were used; all were non-significant

In 1990-91, two NASCIS II recipients and three non-recipients were excluded from this table due to insufficient neurological information to classify. In 1993, five NASCIS II recipients were excluded for this reason; two more were Frankel E at or soon after admission. Among 1993 non-recipients, five could not be classified and six were Frankel E soon after admission. The increase in the number of Frankel $E$ cases probably reflects improved tracking and surveillance

Table 3 Comparison of short term neurological outcomes with use of the NASCIS II protocol (two or more Frankel grades)

(a) 1990-91

\begin{tabular}{|c|c|c|c|c|c|c|}
\hline & \multicolumn{2}{|c|}{$\begin{array}{l}\text { NASCIS II } \\
\quad(n=100)\end{array}$} & \multicolumn{2}{|c|}{$\begin{array}{l}\text { No methylprednisolone } \\
\qquad(n=51)\end{array}$} & \multirow{2}{*}{$\begin{array}{l}\text { \% Improved: } \\
\text { NASCIS III } \\
\text { no methylp. }\end{array}$} & \multirow[t]{2}{*}{$P=a$} \\
\hline & $\begin{array}{l}\text { Frankel class } \\
\text { improvement } \\
\geqslant 2 \text { grades }\end{array}$ & $\begin{array}{c}<2 \text { Frankel } \\
\text { grades } \\
\text { improvement }\end{array}$ & $\begin{array}{l}\text { Frankel class } \\
\text { improvement } \\
\geqslant 2 \text { grades }\end{array}$ & $\begin{array}{c}<2 \text { Frankel } \\
\text { grades } \\
\text { improvement }\end{array}$ & & \\
\hline Frankel A & 14 & 34 & 3 & 9 & $29 \% / 25 \%$ & 0.7744 \\
\hline Frankel B & 7 & 3 & 1 & 2 & $70 \% / 33 \%$ & 0.2522 \\
\hline Frankel C & 0 & 13 & 1 & 6 & $0 / 14 \%$ & \\
\hline Total & 21 & 48 & 5 & 17 & $30 \% / 23 \%$ & 0.4859 \\
\hline
\end{tabular}

(b) 1993

\begin{tabular}{|c|c|c|c|c|c|c|}
\hline \multirow[b]{2}{*}{ Frankel A } & \multicolumn{2}{|c|}{$\begin{array}{c}\text { NASCIS II } \\
(n=88)\end{array}$} & \multicolumn{2}{|c|}{$\begin{array}{l}\text { No methylprednisolone } \\
\qquad(n=39)\end{array}$} & \multirow[b]{2}{*}{$26 \% / 27 \%$} & \multirow[b]{2}{*}{0.9090} \\
\hline & 11 & 32 & 3 & $8^{b}$ & & \\
\hline Frankel B & 3 & 4 & 0 & 0 & $43 \% / 0$ & \\
\hline Frankel C & 2 & 9 & 0 & 0 & $18 \% / 0$ & \\
\hline Total & 16 & 45 & 3 & 9 & $26 \% / 25 \%$ & 0.9423 \\
\hline
\end{tabular}

asee footnote to Table 2

'One individual, known to have developed an 'incomplete injury' was included on the previous table, but was omitted from Table 3 as the extent of the recovery could not be determined. See Table 2 for description of other exclusions from this table 
interpreted as a refutation of Bracken's original findings. ${ }^{\text {Not }}$ only is the Frankel classification system unable to detect neurological change with the same accuracy and sophistication as the sensory and motor testing used in Bracken's study, but this examination of the administration of the NASCIS II protocol in Colorado-as this paper clearly shows-was neither randomized, prospective, consistent, nor systematic. Indeed, herein lies the most important finding of this retrospective study: at least in Colorado, implementation of the NASCIS II protocol for persons with new traumatic spinal cord injuries was neither rapid nor widespread.

It seems unlikely that Bracken's exclusion criteria accounted for most failures to administer the NASCIS II protocol. There seems to be little reason to expect that such criteria, established to ensure methodological purity, would be rigidly followed in actual clinical settings. Even if this was the case, the exclusion criteria seem unable to account for all of Colorado's apparent non-recipients of the protocol. The most readily identifiable exclusions (other severe injuries, gunshot wounds, cauda equina injuries, pregnancy, age less than 13 years) were noted in only about $20 \%$ of the non-protocol cases reviewed: no more than 24 of 118 non-recipient cases in 1990-91, or 13 of 57 in 1993. Although other exclusions, such as narcotics addiction and pre-morbid steroid usage, could not be assessed as easily, it is unlikely that these can begin to account for all of Colorado's remaining non-recipients. Moreover, as Table 1 shows, numerous individuals did receive the NASCIS II protocol, despite the presence of Bracken's exclusions. Though not one of the exclusion criteria, it does appear that early neurological incompleteness or rapidly resolving paralysis was associated with nonadministration of the protocol. Although one-third of those with Frankel Class D injuries did receive the NASCIS II protocol, members of this group still received it significantly less frequently than their more neurologically impaired counterparts. This was true in both study years $(1990-91: P=0.005 ; 1993$ : $P<0.001)$.

In addition, at least during 1990-1991, media publicity was so great that patient refusal was an unlikely explanation for the low administration rate; anecdotal stories abound of patients and families arriving in the emergency department requesting the drug. What remain as possible explanations are failures by physicians to know about the protocol or offer it to their patients, or failures in documentation. Indeed, it is possible that more patients received the NASCIS II protocol than this study indicates, for only clear documentation in the medical record allowed an individual to be classified as a protocol recipient. However, that such large doses of a potent drug might be administered without adequate documentation is almost as concerning as the possibility that a potentially beneficial therapy was not being made available to spinal cord injury survivors. Why the implementation rate was higher for patients seen first for triage is unknown.

With continuing research into pharmacological interventions for individuals with new spinal cord injuries, and the likelihood that other specialized protocols loom on the horizon, additional research is clearly needed to identify what the barriers to more widespread implementation really are.

\section{Acknowledgements}

Funding for this research was provided through a cooperative agreement for the prevention of disabilities, awarded to the Colorado Department of Public Health and Environment by the Centers for Disease Control and Prevention.

\section{References}

1 Bracken $\mathrm{MB}$ et al. A randomized, controlled trial of methylprednisolone or naloxone in the treatment of acute spinal cord injury. $N$ Engl J Med 1990; 322: 1405-1411.

2 Hanigan WC, Anderson RJ. Commentary of NASCIS-2. $J$ Spinal Disord 1992; 5: 125-131.

3 Walker MD. Clinical Alert. National Institute on Neurological Disorders and Stroke. Public Health Services: National Institute of Health. US Department of Health \& Human Services: Bethesda, Maryland, 1990.

4 Weiss R. Drug reduces paralysis after spinal injury. Science News 1990; 137: 212

5 Leary W. Treatment is said to reduce disability from spinal injury. New York Times, March 31, 1990.

6 World Health Organization. World Health Organization International Classification of Impairments, Disabilities and Handicaps: a Manual of Classification Relating to the Consequences of Disease. World Health Organization: Geneva, 1980.

7 Colorado Department of Health. 1993 Annual Report of the Spinal Cord Injury Early Notification System. Colorado Department of Transportation Printing Office: Denver, Colorado, 1994.

8 Frankel $\mathrm{H}$ et al. The value of postural reduction in the initial management of closed injuries to the spine with paraplegia and tetraplegia. Paraplegia 1969; 7: 179-192. 